\title{
Evaluation of Models for Estimating Shrinkage Stress in Patch Repair System
}

\author{
Stefanus A. Kristiawan*
}

(Received August 23, 2012, Accepted November 2, 2012)

\begin{abstract}
Cracking of repair material due to restraint of shrinkage could hinder the intended extension of serviceability of repaired concrete structure. The availability of model to predict shrinkage stress under restraint condition will be useful to assess whether repair material with particular deformation properties is resistance to cracking or not. The accuracy in the prediction will depend upon reliability of the model, input parameters, testing methods used to characterize the input parameters, etc. This paper reviews a variety of models to predict shrinkage stress in patch repair system. Effect of creep and composite action to release shrinkage stress in the patch repair system are quantified and discussed. Accuracy of the models is examined by comparing predicted and measured shrinkage stress. Simplified model to estimate shrinkage stress is proposed which requires only shrinkage property of repair material as an input parameter.
\end{abstract}

Keywords: cracking, prediction model, repair, restraint, shrinkage stress, simplified model.

\section{Introduction}

Spalling of concrete cover is an indication of degradation that could impair the performance of reinforced concrete structure in service. This type of damage could be due to reinforcement corrosion or other causes. Patch repair is a common method to recover the size and appearance of this damaged concrete, protect the exposed reinforcement from further corrosion and partially regain its structural capacity. The effectiveness of this repair method to restore damaged reinforced concrete is controlled by the performance and durability of the patch repair material being used.

Matthews (2007) investigated performance of repair materials via case histories and found a variety of modes of repair failure. The principle modes of repair failure were cracking (32\%), debonding (25\%), continued corrosion of embedded reinforcement $(22 \%)$, alkali aggregate reaction (4\%) and others $(17 \%)$. In term of cracking, this mode of repair failure could be triggered by restraint of drying shrinkage. As repair material is applied on top of damaged concrete, they turn into composite system. The new repair material will shrink considerably while the shrinkage of the substrate concrete is negligible. This differential shrinkage creates restraint to the deformation of repair material. In turn, tensile stress is induced in the repair material. If the induced

Civil Engineering Department, Sebelas Maret University, Jl. Ir. Sutami No. 36 A, Surakarta 57126, Indonesia.

*Corresponding Author;

E-mail: sa_kristiawan@sipil.ft.uns.ac.id

Copyright $($ The Author(s) 2012. This article is published

with open access at Springerlink.com tensile stress (termed as shrinkage stress) exceed tensile capacity of repair material, it will cause cracking in the repair material.

Assessment of repair material performance related to shrinkage cracking has been suggested in literatures and may be categorized into three methods. The first method is to limit the magnitude of shrinkage as a criterion to determine the cracking tendency of repair material. The basis of this method is an assumption that material with a higher shrinkage property should have a higher risk of cracking and vice versa. Limitation of magnitude of shrinkage has been specified in several standards and literatures (ASTM 2000, 2007; Hongkong Housing Authority 1991; McDonald et al. 2000). Suitability of performance assessment based on a limitation of shrinkage value alone may be inaccurate since cracking is not affected only by shrinkage, but other parameters such as creep and elastic modulus are also involved. As noted by Mc Donald et al. (2000), there is no correlation between restricting shrinkage with the field performance. This is an indication that more reliable performance assessment is required which should take into account other parameters as criteria.

Method of shrinkage cracking assessment is improved when parameters influencing cracking behaviour of repair material under restrained condition are reckoned. An example of the method is a measurement of shrinkage cracking on ring specimen where restraint is provided by inner steel ring. This method has been standardized in AASHTO PP34-99 (2006) and ASTM C1581 (2007). There are slightly differences in the dimension of the ring test between those two standards. Parameters observed during the test include time to first cracking, number of cracks and width of cracks. The stress occured in repair material could also be determined from measurement of strain on inner steel 
ring. Parameters observed in this test are product of interaction between shrinkage, creep and elastic strain property of repair material. Thus, this method measures a better and proper behaviour of repair material under restrained shrinkage condition in comparison to limitation of shrinkage method. However, it is noted that this test method is only capable to be used to compare cracking resistance between various repair materials (Bentur and Kovler 2003). This method does not have a link to correlate cracking resistance of repair material as observed in this test with its field performance. This is because cracking behaviour of repair material is not only affected by deformation properties of repair material, but it is also influenced by degree of restraint (termed as a fraction of shrinkage being restrained that causes shrinkage stress) which in this test depends upon elastic property of inner steel ring and dimension of ring. In actual (field) performance, the degree of restraint is dependent on bonding between repair material and substrate, deformation properties and dimension of substrate.

A better method to asses cracking tendency of repair material is by quantifying the development of tensile stress induced by restrained shrinkage and compared the value with tensile capacity of repair material. The development of tensile stress due to restrained shrinkage (defined as shrinkage stress) in the repair system is affected by magnitude of drying shrinkage, creep and modulus of elasticity of repair material. In addition, properties of the substrate concrete will also influence the magnitude of induced stress. Many models have been suggested to calculate shrinkage stress under restraint condition. In the development of the models, restraint of shrinkage could be provided by end restraint, base restraint or inner steel ring restraint as illustrated in Fig. 1 (Carlsward 2008). For end restraint type, the shrinkage stress occured in repair material solely depends upon shrinkage, creep and elastic properties of repair material. For base restraint type, there is an interaction between repair material and substrate concrete which affects the magnitude of shrinkage stress. Thus in addition to shrinkage, creep and elastic properties of repair material, the magnitude of shrinkage stress is also influenced by degree of bonding between repair material and substrate, deformation properties of substrate, the dimension of patch repair system, etc. For inner steel ring restraint, elastic property of steel ring, dimension of ring and deformation properties of repair material will determine the shrinkage stress occurred in repair material. Among the three type of restraints as described above, substrate restraint is thought to be properly reflecting the actual restraint in patch repair system.

Quantification of shrinkage stress using prediction model could provide rational tool to assess a risk of cracking in patch repair system. Accuracy of the model will be a key in developing such method of assessment. The aims of this paper is to review models which may be applied to predict shrinkage stress in patch repair system. Effect of creep and composite action to release stress considered by the models will be quantified theoretically and using input parameters extracted from various literatures. Accuracy of the models are examined by comparing the predicted shrinkage stress with shrinkage stress data obtained in literature. Simplified model to estimate shrinkage stress is proposed which is derived from correlation between shrinkage and the induced stress.

\section{Review of Shrinkage Stress Prediction Models}

The stress induced by restrained shrinkage in patch repair system may be calculated by examining Fig. 2 as follows: at the start of repair material being applied on top of substrate concrete, those two materials are in equilibrium state (Fig. 2a). As time increases, a new repair material will shrink at significantly a higher rate than old substrate concrete. If the two materials could experience shrinkage independently, the repair material would exhibit shrinkage at a magnitude of $\varepsilon_{s h-r(t)}$ at time $t$ while the substrate concrete will shrink at a magnitude of $\varepsilon_{s h-s(t)}$ (Fig. 2b). However, since repair material develops bond to the substrate, consequently it turns repair material and substrate becoming a composite system. The movement of repair material will be restrained by substrate. If it is assumed that full restraint is occurred, then the magnitude of shrinkage of repair material being restrained is equivalent to $\Delta_{\varepsilon s h(t)}$ which is the differential shrinkage between repair material and substrate concrete. When shrinkage of repair material is restrained, tensile stress, $\sigma_{(t)}$, is induced which is equivalent to the stress required to pull the repair material at an elongation of $\Delta_{\varepsilon s h(t)}$ (Fig. 2c). The magnitude of induced tensile stress is going up in time following increase of shrinkage. However, there are factors which could relieve the magnitude of tensile stress i.e. elastic and creep property of repair material in tension. Thus, the final induced tensile stress may be expressed in the following equation:

$$
\begin{aligned}
& \sigma_{(t)}=E_{(t)}\left(\Delta \varepsilon_{s h(t)}-\varepsilon_{e l(t)}-\varepsilon_{c r p(t)}\right) \\
& \sigma_{(t)}=E_{(t)}\left(\Delta \varepsilon_{s h(t)}-\frac{\sigma_{(t)}}{E_{(t)}}-\frac{\sigma_{(t)}}{E_{(t)}} \phi_{(t)}\right) \\
& \sigma_{(t)}=\frac{E_{(t)}}{\left(2+\phi_{(t)}\right)} \Delta \varepsilon_{s h(t)}
\end{aligned}
$$

where $\sigma_{(t)}, E_{(t)}, \Delta \varepsilon_{s h(t)}, \varepsilon_{e l(t)}, \varepsilon_{c r p(t)}$ and $\phi_{(t)}$ are respectively shrinkage stress, elastic modulus, differential shrinkage, elastic strain, creep and creep coefficient at time $t$.

Equation (1.c) could be applied to calculate shrinkage stress for finite time interval $\left(t_{i+1}-t_{i}\right)$ and so Eq. (1.c) becoming:

$$
\Delta \sigma_{\left(t_{i+1}-t_{i}\right)}=\frac{E_{\left(t_{i+1}\right)}}{\left(2+\phi_{\left(t_{i+1}-t_{i}\right)}\right)} \Delta \varepsilon_{s h\left(t_{i+1}-t_{i}\right)}
$$

From Eq. (2), shrinkage stress in repair material could be estimated as cumulative of $\Delta \sigma_{(t i+1-t i)}$ :

$$
\sigma_{\left(t_{n}\right)}=\sum_{t_{i}=0}^{t_{n}} \Delta \sigma_{\left(t_{i+1}-t_{i}\right)}
$$

Shrinkage stress estimated using Eqs. (2-3) could be reduced when full restraint of shrinkage is not achieved due 


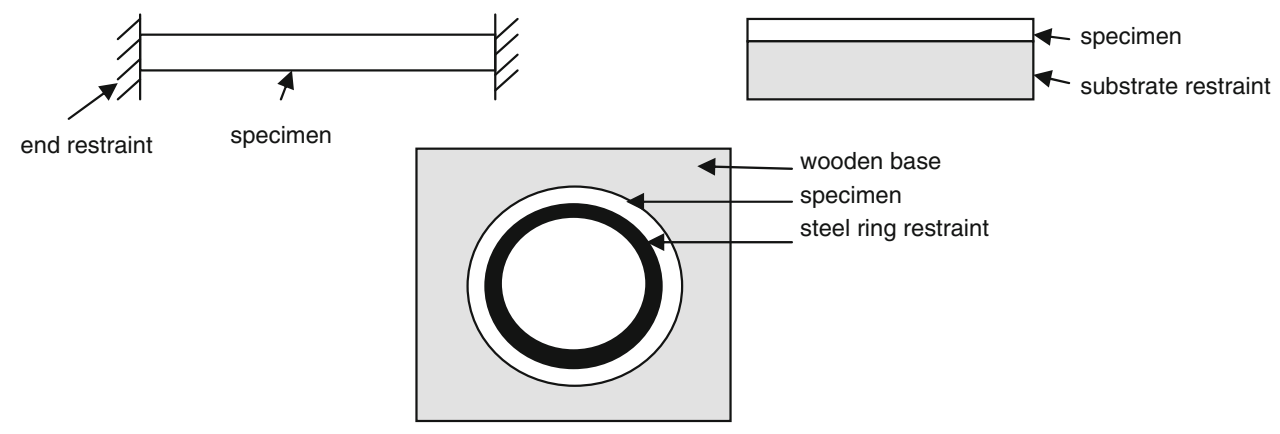

Fig. 1 Type of restraints.

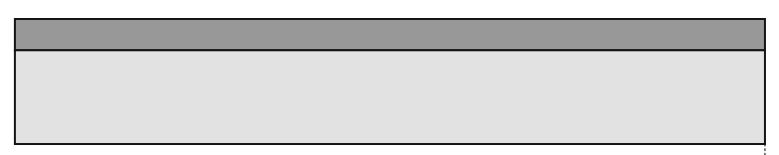

(a)

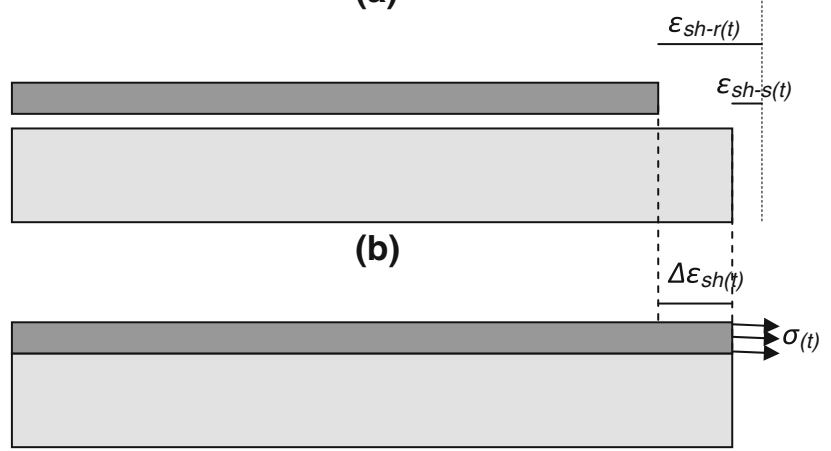

(c)

Fig. 2 The magnitude of shrinkage induces stress in repair system.

to imperfect bonding between repair material and substrate concrete. In this situation, only a fraction of differential shrinkage, $\Delta_{\varepsilon s h(t)}$, is restrained. Other factors could also reduce the value of differential shrinkage, $\Delta_{\varepsilon s h(t) \text {, for }}$ example due to deformation of substrate concrete. Hence, if $\mu$ represents a fraction (degree) of restraint, then magnitude of shrinkage that will induce stress is $\mu \Delta_{\varepsilon s h(t) \text {. }}$. The value of $\mu$ is between zero and one.

Further assessment of Fig. 2c, it is noted that when tensile stress occurred in repair material the system is on condition of unbalance forces. For equilibrium of forces, a compressive force of $N=\sigma_{(t)}$. $A_{r}$ is required to be applied on the system at the center of gravity of repair material where $A_{r}$ representing cross-section area of repair material. This compressive force $N$ causes the composite system undergoes two type of compressive stresses i.e. axial stress $\sigma_{N}$ due to compressive force $N$ applied on the center of gravity of composite and bending stress $\sigma_{M}$ due to moment $M=N \cdot y_{c}$ where $y_{c}$ is distance between center of gravity of repair material and composite (see Fig. 3). These two type of stresses have releasing effect on the shrinkage stress of repair material (Denarie et al. 2011). Thus, the final stress occurred in repair material $\sigma_{\text {new }(t)}$ becomes:

$$
\sigma_{\text {new }(t)}=\sigma_{(t)}-\sigma_{N}-\sigma_{M}
$$

It is obvious that $\sigma_{N}$ is distributed evenly across the section of repair material while $\sigma_{M}$ distributed linearly with the minimum at the interface between repair material and substrate concrete. For evaluation of shrinkage stress, the use of $\sigma_{M}$ at the interface will give a conservative value of shrinkage stress. The values of both $\sigma_{N}$ and $\sigma_{M}$ depend upon elastic modulus and dimension of both repair material and substrate concrete.

In the development of model to predict shrinkage stress as given above, the only time-dependent deformation property of substrate concrete which has been taken into account is shrinkage while creep is omitted. If shrinkage of substrate concrete is negligible, the differential shrinkage that causes shrinkage stress is equivalent to shrinkage of repair material itself. The elimination of substrate shrinkage could be accepted when substrate concrete being repaired is that of old concrete.

A different model has been proposed by Silfwerbrand (1996) where shrinkage stress $\sigma_{(t)}$ may be calculated using the following equations:

$$
\begin{aligned}
& \sigma_{(t)}=\mu E_{(t)}^{*} \varepsilon_{s h(t)} \\
& \mu=\frac{m(1-\alpha)\left\{m\left(1-\alpha^{3}\right)+\alpha^{2}(3+\alpha)\right\}}{m+(m-1)\left\{m\left(1-\alpha^{4}\right)-\alpha^{4}\right\}} \\
& E^{*}=\frac{E_{1}}{\left(1+\phi_{(t)}\right)}
\end{aligned}
$$

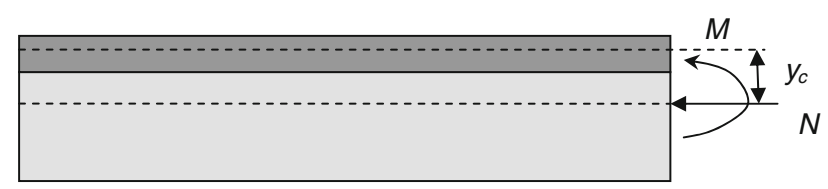

(a)

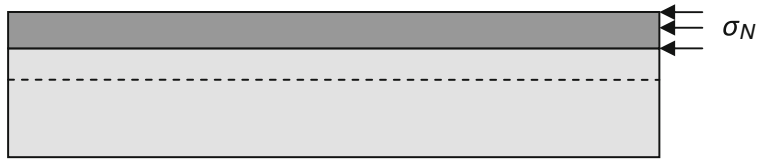

(b)

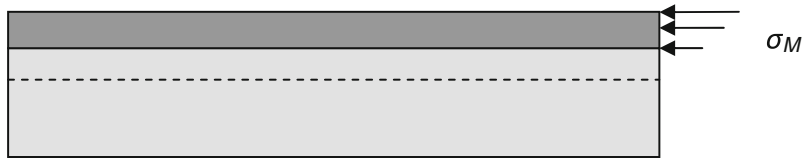

(c)

Fig. 3 Compressive stresses in repair material due to balancing compressive force. 
where $\varepsilon_{s h}, E_{(t)}^{*}$ and $\mu$ are shrinkage of repair material, modified elastic modulus of repair material and degree of restraint, respectively. Equation (5.a) indicates that stress induced by shrinkage is partially released by creep and a form of restraint. This restraint is due to stress distribution on composite system where Bernoulli's hypothesis i.e. plane sections remain plane after bending is applied. The value of degree of restraint is always less than one and it is affected by $m$ and $\alpha$ which are, respectively, ratio of elastic modulus of substrate concrete $E_{2}$ to $E^{*}$ and ratio of depth of repair material $d$ to total thickness of overlay plus substrate concrete $h$. Creep coefficient $\phi_{(t)}$ is used to obtain $E^{*}$ from elastic modulus of repair material $E_{1}$. Thus, creep is taken into account to modify the value of elastic modulus of repair material and so its value is reduced. Several assumptions have been used for developing this shrinkage stress prediction model and those which represent parameters related to mechanism of shrinkage induces stress in repair material are outlined as follows: the shrinkage of repair material is $\varepsilon_{s h}$ throughout the depth of material while shrinkage of concrete substrate is neglected; complete bond exists in the interface of repair material and substrate which provides full restraint of shrinkage; creep of the substrate concrete is negligible.

Carlsward (2008) proposed similar model with that of Silwerbrand. The only difference is that the method of Silfwerbrand is a one-step calculation i.e. a single stress value is calculated based on the final shrinkage whereas the method of Carlsward is an incremental procedure. The stress at any time $t$ due to shrinkage applied at time $t_{i}$, is estimated using the following equations:

$$
\begin{aligned}
& \sigma_{\left(t, t_{i}\right)}=\mu E_{\left(t, t_{i}\right)}^{*} \varepsilon_{s h\left(t_{i}\right)} \\
& \mu=\frac{m_{\left(t, t_{i}\right)}(1-\alpha)\left\{m_{\left(t, t_{i}\right)}\left(1-\alpha^{3}\right)+\alpha^{2}(3+\alpha)\right\}}{m_{\left(t, t_{i}\right)}+\left(m_{\left(t, t_{i}\right)}-1\right)\left\{m_{\left(t, t_{i}\right)}\left(1-\alpha^{4}\right)-\alpha^{4}\right\}} \\
& E_{\left(t, t_{i}\right)}^{*}=\frac{E_{1\left(t, t_{i}\right)}}{\left(1+\phi_{\left(t, t_{i}\right)}\right)}
\end{aligned}
$$

The total stress at any time $t$ is calculated by summing the contribution from each increment as:

$$
\sum_{i=1}^{1} \sigma_{\left(t, t_{i}\right)}
$$

Other model to estimate shrinkage stress is proposed by Baluch et al. (2002) where shrinkage stress at time $t, \sigma(t)$, is computed by multiplying elastic modulus of repair material $E_{(t)}$ with total strain, in which total strain in repair material is obtained from shrinkage $\varepsilon_{s h(t)}$ minus creep $\varepsilon_{c r p(t) \text {. The }}$ contribution of elastic strain of repair material is omitted. The model is also developed by assuming that time-dependent deformation properties of substrate concrete are negligible. In addition, rigidity of substrate concrete is incomparable than that of repair material. In turn, effect of elastic deformation of substrate concrete could be ignored. This can be achieved when the size (thickness) of substrate concrete is far greater than that of repair material. Obviously, these assumptions lead to similarity of the model with end restraint situation. The model is expressed in the following equations:

$$
\sigma_{(t)}=E_{t}\left(\varepsilon_{s h(t)}-\varepsilon_{c r p(t)}\right)
$$

The value of creep may be expressed in term of specific creep $c_{(t)}$ defined as creep due to unit of stress. Hence, Eq. (8.a) turns to be:

$$
\sigma_{(t)}=\frac{E_{t} \varepsilon_{s h(t)}}{\left(1+E c_{(t)}\right)}
$$

Many more models could be found in literatures (Weiss et al. 1998; Yang et al. 2000; Zhou et al. 2008; Raoufi et al. 2011). Computation of shrinkage stress using these models require numerical techniques which are beyond the scope of this paper.

\section{Comparison of Shrinkage Stress Computed from Different Models}

\subsection{Input Parameters}

Computation of shrinkage stress in patch repair system using a variety of prediction models requires input parameters which are determined experimentally. The input parameters at least consist of shrinkage, creep and elastic property of repair material. When effect of deformation properties of substrate concrete are taken into account, the models require another input parameters to be determined i.e. shrinkage, creep and elastic property of substrate concrete. The effect of releasing stress due to composite action could be included and for this reason dimension (thickness) of both repair material and substrate concrete are necessary.

Various experimental results found in literatures are gathered to be used as input parameters for this current study. Type of material, dimensions of specimens, testing methods, age of testing and other relevance condition for measuring input parameters obtained from various sources are presented in Table 1. With data extracted from these sources, the main parameters influencing the shrinkage stress are investigated.

\subsection{Degree of Restraint and Stress Release}

Various models as presented in previous section would be expected to give dissimilarity in the results of shrinkage stress prediction. The difference in estimating shrinkage stress calculated using various models could be identified from the degree of restraint and stress release considered by each model. If the magnitude of shrinkage of repair material at time $t$ is $\varepsilon_{s h(t)}$, the shrinkage stress at time $t$ is equivalent to $\sigma_{\varepsilon s h(t)}=E \cdot \varepsilon_{s h(t)}$ when full degree of restraint is assumed. However, these shrinkage stress will be reduced due to effect of creep and so, the value of elastic modulus $E$ is modified by $E_{(t)}$ to account for creep at time $t$. The reduction in shrinkage stress may also be viewed as a reduction of the degree of restraint. Hence, the degree of restraint due to 
Table 1 Sources of input parameters.

\begin{tabular}{|c|c|c|c|c|}
\hline \multicolumn{4}{|c|}{ Information related to input parameters } & \multirow[t]{2}{*}{ Source of data } \\
\hline Material & Shrinkage & Creep & Elastic modulus & \\
\hline $\begin{array}{c}\text { Repair material and } \\
\text { substrate are concrete } \\
\text { with compressive cube } \\
\text { strength of } 48 \text { and } 52 \mathrm{MPa} \\
\text { at } 28 \text { days, } \\
\text { respectively; thickness } \\
\text { of repair material and } \\
\text { substrate are } 50 \text { and } \\
100 \mathrm{~mm} \text {, respectively }\end{array}$ & $\begin{array}{l}\text { Specimen: prism of } \\
400 \times 10 \times 100 \mathrm{~mm} \text {; } \\
\text { tested according to } \\
\text { Swedish Standard SS } \\
13721 ; \text { measurement } \\
\text { started } 7 \text { days after } \\
\text { casting }\end{array}$ & $\begin{array}{c}\text { Specimen: prism } \\
400 \times 100 \times 100 \mathrm{~mm} \text {, } \\
\text { loaded incrementally in } \\
\quad \text { compression; } \\
\text { measurement started at } \\
7 \text { days after moistening }\end{array}$ & $\begin{array}{c}\text { Estimated to } \mathrm{E}=34 \mathrm{GPa} \\
\text { through evaluation of } \\
\text { compressive stress on } \\
\text { cubes }\end{array}$ & Silfwerbrand (1996) \\
\hline $\begin{array}{l}\text { Repair material is high } \\
\text { performance shrinkage } \\
\text { compensated repair } \\
\text { concrete; substrate } \\
\text { concrete is normal } \\
\text { concrete; thickness of } \\
\text { repair material and } \\
\text { substrate are } 25 \text { and } \\
50 \mathrm{~mm} \text {, respectively }\end{array}$ & $\begin{array}{l}\text { Specimen: prism of } \\
285 \times 25 \times 25 \mathrm{~mm} \text {; } \\
\text { sealed in aluminium foil } \\
\text { for } 7 \text { days prior to } \\
\text { curing }\end{array}$ & $\begin{array}{c}\text { Specimen: prism of } \\
300 \times 40 \times 40 \mathrm{~mm} \\
\text { loaded in tensile creep } \\
\text { rig }\end{array}$ & $\begin{array}{l}\text { Evaluated according to } \\
\text { ASTM C 307-94 }\end{array}$ & $\begin{array}{l}\text { Baluch et al. (2002), } \\
\text { Carlsward (2006) }\end{array}$ \\
\hline $\begin{array}{l}\text { Repair material is mortar } \\
\text { while substrate is concrete } \\
\text { having compressive } \\
\text { strength of } 25 \mathrm{MPa} \\
\text { thickness of repair } \\
\text { material and substrate are } \\
30 \text { and } 150 \mathrm{~mm} \text {, } \\
\text { respectively }\end{array}$ & $\begin{array}{l}\text { Specimen: cylinder of } \\
7.5 \times 275 \mathrm{~mm} \text {; } \\
\text { measurement started at } \\
1 \text { days after casting }\end{array}$ & $\begin{array}{l}\text { Specimen: prism of } \\
500 \times 100 \times 100 \mathrm{~mm} \\
\text { loaded in flexure; } \\
\text { measurement started at } \\
1 \text { days after casting }\end{array}$ & $\begin{array}{l}\text { Specimen:prism of } \\
500 \times 100 \times 100 \mathrm{~mm} ; \\
\text { tested in flexure in which } \\
\text { stress and strain } \\
\text { relationship in tension } \\
\text { was determined }\end{array}$ & Kristiawan et al. (2009) \\
\hline $\begin{array}{l}\text { Repair material is fibre } \\
\text { reinforced concrete with } \\
\text { strength at } 28 \text { days is } \\
51.5 \mathrm{MPa} \text {; thickness of } \\
\text { repair and substrate } \\
\text { concrete are } 50 \text { and } \\
300 \mathrm{~mm} \text {, respectively }\end{array}$ & $\begin{array}{l}\text { Specimen: prism of } \\
500 \times 100 \times 50 \mathrm{~mm} \text {; } \\
\text { measurement started } \\
5 \text { days after curing }\end{array}$ & $\begin{array}{l}\text { Specimen: cylinder of } \\
150 \times 300 \mathrm{~mm} \text { loaded } \\
\text { in compression }\end{array}$ & $\begin{array}{l}\text { Estimated based on } \\
\text { compressive strength } \\
\text { using CEB FIP MC90 }\end{array}$ & $\begin{array}{c}\text { Carlsward (2008), Rahman } \\
\text { et al. (2000) }\end{array}$ \\
\hline
\end{tabular}

effect of creep, $\mu_{\phi}$, of repair material could be quantified as the following:

a. $\mu_{\phi}^{*}=\frac{1}{\left(2+\phi_{t}\right)}$ for Eq. (1.c).

b. $\quad \mu_{\phi}=\frac{1}{(1+\phi)}$ for model of Silfwerbrand (Eqs. (5.a-5.c))

c. $\mu_{\phi}=\frac{1}{\left(1+\phi_{\left(t, t_{i}\right)}\right)}$ for model of Carlsward (Eqs. (6.a-6.c))

d. $\quad \mu_{\phi}=\frac{1}{\left(1+E_{t} c_{t}\right)}=\frac{1}{\left(1+\phi_{t}\right)}$ for model of Baluch et al. (Eq. (8.b))

The degree of stress release due to effect of creep $\psi_{\phi}$ will be:

a. $\psi_{\phi}^{*}=1-\mu_{\phi}^{*}=1-\frac{1}{\left(2+\phi_{t}\right)}$ for Eq. (1.c)

b. $\psi_{\phi}=1-\mu_{\phi}=1-\frac{1}{(1+\phi)}$ for model of Silfwerbrand (Eqs. $(5 . a-5 . c))$

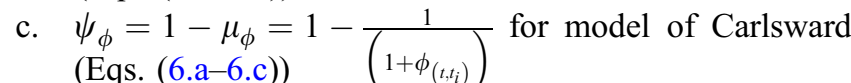

d. $\psi_{\phi}=1-\mu_{\phi}=1-\frac{1}{\left(1+\phi_{t}\right)}$ for model of Baluch et al. (Eq. (8.b)).

Comparison of degree of restraint due to effect of creep, $\mu_{\mathscr{\sigma}}$, of repair material accounted by various models is presented in
Figs. 4 and 5. It is obvious that effect of creep to release stress is similar for model of Silfwerbrand (Eq. (5.a)), Carlsward (Eq. (6.a)) and Baluch et al. (Eq. (8.b)). On the other hand, in addition to creep effect, influence of elastic strain to release stress is also included in Eq. (1.c). Therefore, the degree of restraint $\mu_{\phi}$ used in Eq. (1.c) is lower than others. To reckon the influence of elastic strain in releasing stress, superscript asterisk is used in the notation of degree of restraint $\mu_{\phi}^{*}$. Based on data of creep coefficient $\left(\phi_{(t)}\right)$ and elastic modulus extracted from Baluch et al. (2002) as input parameters, the value of $\mu_{\phi}$ of Eq. (1.c) is about 10-20\% below those of other models (Fig. 4). For the whole data extracted from sources shown in Table 1, the different between degree of restraint $\mu_{\phi}$ of Eq. (1.c) with those of other models could be quantified using polynomial expression as shown in Fig. 5. It is seen that the values of $\mu_{\phi}$ is in the range of $0.1-0.9$ and it is reduced by about $40 \%$ if effect of elastic strain is reckoned as in Eq. (1.c).

In the meantime, the degree of restraint due to composite action, $\mu_{c}$, used in Eqs. (5.a) and (6.a) could also be identified from Eqs. (5.b) and (6.b), respectively. In the development of model to predict shrinkage stress, the values of $\mu$ 


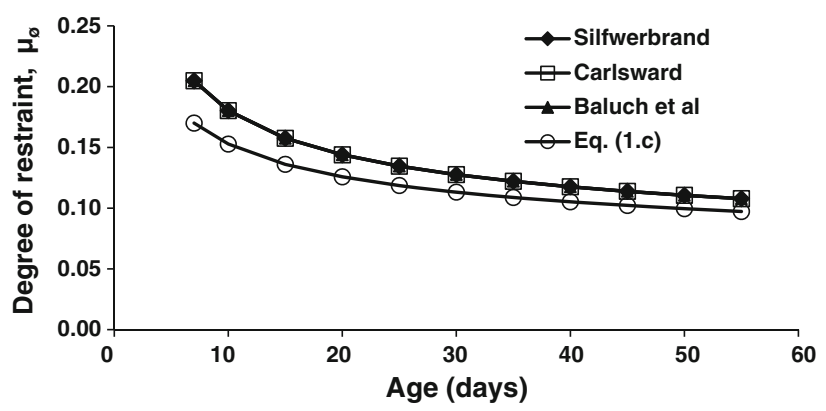

Fig. 4 Degree of restraint due to creep effect $\mu_{\phi}$ calculated using input parameters extracted from Baluch et al. (2002).

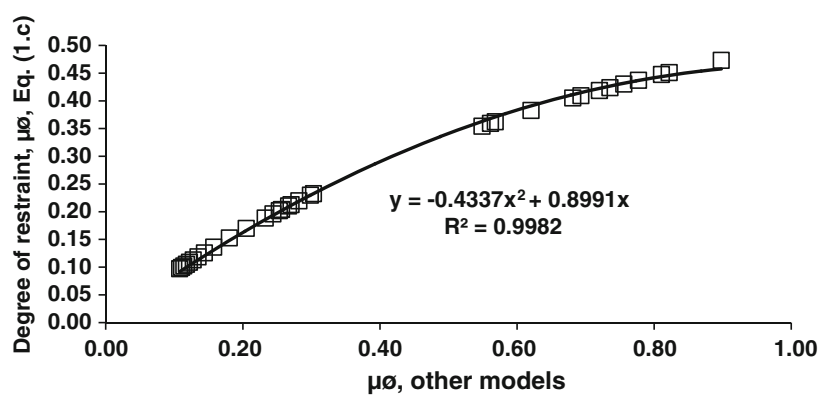

Fig. 5 Relationship between degree of restraint due to creep effect $\mu_{\phi}$ calculated from Eq. (1.c) and other models.

in Eqs. (5.b) and (6.b) are derived from composite beam theory where Bernoulli's hypothesis is applied. Thus, it can be deduced that the value $\mu$ represents the degree of restraint due to composite action $\mu_{c}$. For Eq. (4) the value of $\mu_{c}$ is equivalent to:

$$
\begin{aligned}
& \mu_{c}=\frac{\sigma_{(t)}-\sigma_{N}-\sigma_{M}}{\sigma_{(t)}} \\
& \mu_{c}=1-\psi_{N}-\psi_{M}
\end{aligned}
$$

where $\psi_{N}$ and $\psi_{M}$ representing degree of stress release due to axial and bending action, respectively.

Figures 6 and 7 show degree of restraint and stress releases due to composite action in the repair system for cases of beam having total thickness (included thickness of repair material) of $300 \mathrm{~mm}$. For this parametric study, value of relative thickness of repair material to total thickness of composite system $\alpha$ is limited to 0.333 which corresponds to a maximum repair material thickness of $100 \mathrm{~mm}$. This depth of repair material is thought to be a representation of maximum depth of general patch repair on beam having depth of $300 \mathrm{~mm}$. Generally, it is found that degree of stress release due to composite action used in Eq. (4) $\mu_{c}$ has exactly similar value with $\mu$ used in Eq. (5.a). The similarity of degree of stress release of both equations is not surprising since both of them derived from similar principle of composite action. It is also seen that for cases as in Figs. 6 and 7, the value of $\mu_{c}$ is in the range of $0.44-0.87$.

Effect of $\alpha$ is investigated at relative ratios of effective modulus of substrate concrete to repair material $m=1$ (See Fig. 6). It is confirmed that degree of restraint due to composite action decreases at diminishing rate when $\alpha$ is

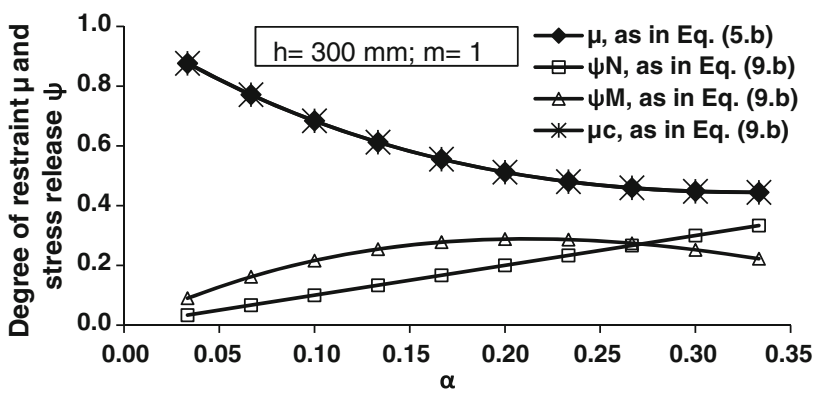

Fig. 6 Degree of restraint $\mu$ and stress release $\psi$ due to composite action on a beam with $300 \mathrm{~mm}$ thickness and $\mathrm{m}=1$ at various $\alpha$.

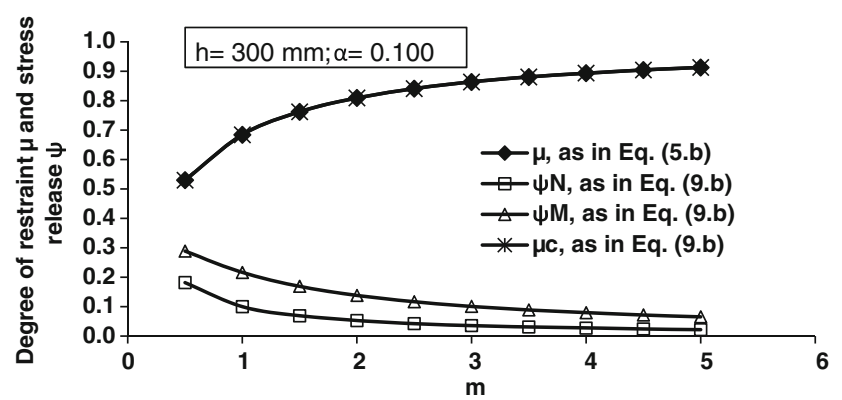

Fig. 7 Degree of restraint $\mu$ and stress release $\psi$ due to composite action on a beam with $300 \mathrm{~mm}$ thickness and $\alpha=0.100$ at various $m$.

increased linearly. Examining Fig. 6, it is also discovered that the component of axial stress release $\psi_{N}$ increases linearly with $\alpha$. On the contrary, the component of bending stress release $\psi_{M}$ increases in the beginning (lower $\alpha$ ) and then reaching a peak value before decreasing. It is also seen that $\psi_{N}$ is inferior than $\psi_{M}$ especially at lower $\alpha$, but the trend is reversed at a higher $\alpha$.

Effect of $m$ on degree of restraint could be examined from Fig. 7. An opposite trend is shown if it is compared with the effect of $\alpha$. The degree of restraint due to composite action accounted in Eqs. (4) and (5.a) increase at diminishing rate. This behaviour is related to reduction of both $\psi_{N}$ and $\psi_{M}$ as $m$ increased. Thus, if relative property of elastic modulus of substrate concrete to repair material is increased continuously, the amount of stress released by axial and bending action in the composite system is reduced and approaching zero value. Consequently, degree of restraint is increased and shrinkage stress approach to its original value when stress release due to composite action is omitted.

\subsection{Magnitude of Shrinkage Stress Estimated by Various Models}

An example result of shrinkage stress calculation are given in Fig. 8 using input parameters extracted from Baluch et al. (2002). As can be seen in this figure, different model will give different value of shrinkage stress with the higher shrinkage stress is obtained from the use of Eq. (8.b) or model of Baluch et al. followed by Eq. (1.c), and then Eq. (5.a) or model of Silfwerbrand and Eq. (6.a) or model of Carlsward. The lowest shrinkage stress is obtained with the use of Eq. (4). 
The order of shrinkage stress values as seen in Fig. 8 is predictable and could be related to the degree of stress releases considered by the models. Examining all the models as described in the previous section, it is clear that the stress release consists of two components i.e. due to effect of creep of repair material and due to effect of composite action. For model of Eq. (1.c), it considers not only stress release by creep but it also takes into account influence of elastic property of repair material. Meanwhile, the effect of composite action to release stress in repair material is neglected in Eqs. (1.c) and (8.b). None of the models takes into consideration other stress release which is caused by deformation properties of substrate concrete. Model prediction which consider all possibilities of stress releases i.e. (Eq. (4)) will give the lowest magnitude of shrinkage stress and vice versa. Figure 9 illustrates the magnitude of shrinkage stress computed by various models from its original value $\left(\sigma_{\varepsilon s h(t)}\right)$. Original shrinkage stress $\sigma_{\varepsilon s h(t)}$ is a stress calculated where none of degree of restraint is considered.

Comparison between shrinkage stress calculated using Eq. (8.b) and other models with input parameters taken from various sources (Table 1) is given in Fig. 10. Equation (8.b) could be viewed as the basic shrinkage stress prediction model where only stress release due to creep effect has been taken into account. If other stress releases would be included, the magnitude of shrinkage stress should be reduced. Figure 10 clearly illustrates this situation. Generally, it can be said that elastic property of repair material could reduce shrinkage stress by $40 \%$ (see relationship Eqs. (8.b) vs. (1.c) in Fig. 10). Composite action could release shrinkage stress at $10 \%$ more than effect of elastic property of repair material. Combination of elastic property and composite action could bring shrinkage stress down to $29 \%$ (see relationship Eqs. (8.b) vs. (4) in Fig. 10).

\section{Accuracy of the Models}

Accuracy of the model to estimate shrinkage stress in patch repair system could be evaluated when concurrent data of input parameters and observed shrinkage stress are available. However, it is difficult to establish shrinkage stress measurement induced by substrate restraint which reflects actual deformation properties of substrate concrete. The available complete input parameters and shrinkage stress

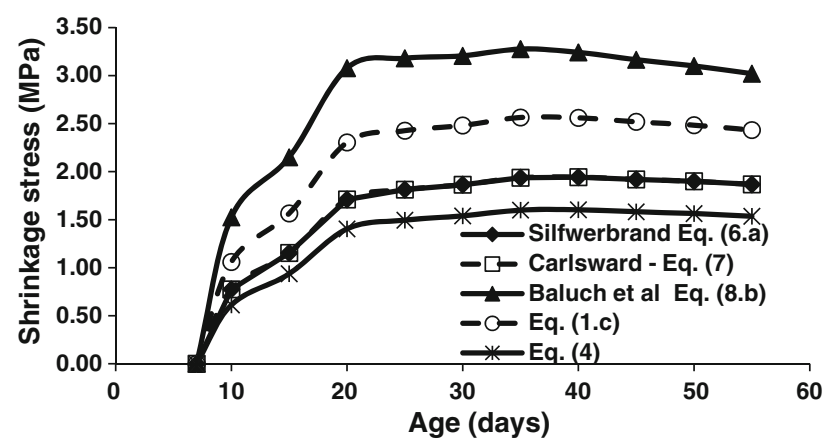

Fig. 8 Shrinkage stress estimated by different models (input parameters extracted from Baluch et al. 2002).

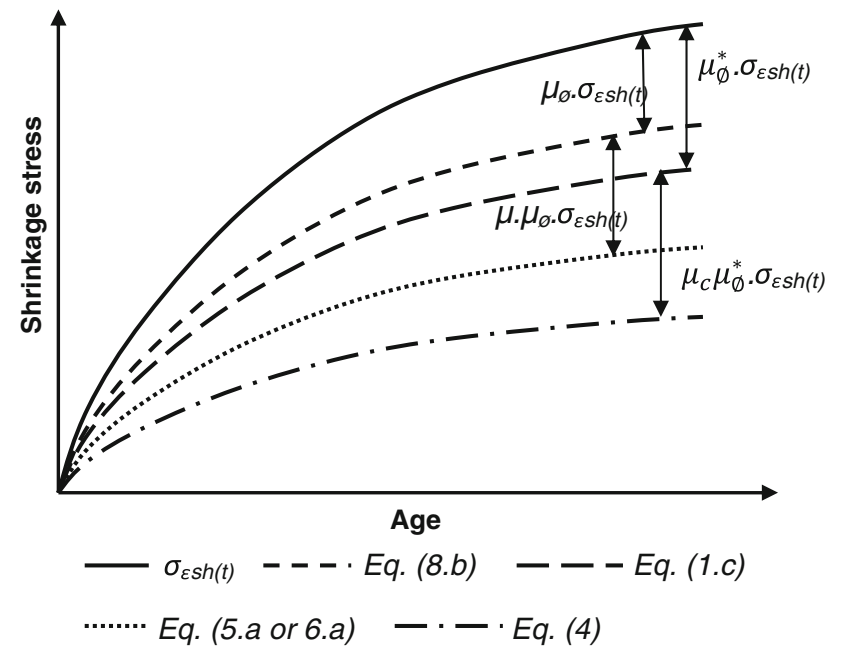

Fig. 9 Magnitude of shrinkage stress as influenced by degree of restraint.

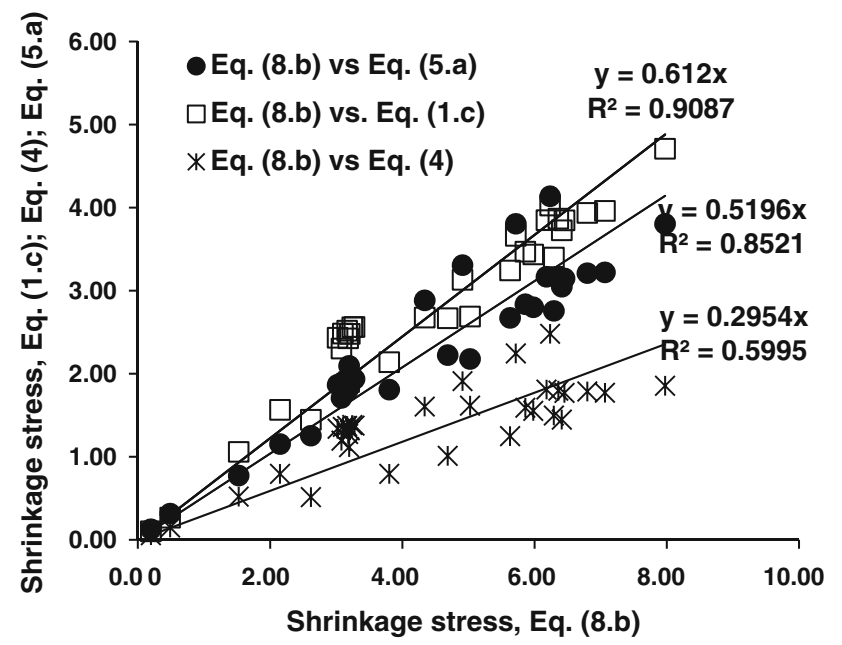

Fig. 10 Relation between shrinkage estimated by Eq. (8.b) with other models.

data for evaluation of the models are those obtained from measurement of shrinkage stress induced by end restraint (Lange et al. 2003). If these data are used, only Eqs. (1.c) and (8.b) may be evaluated since these models neglecting the effect of substrate concrete properties.

Table 2 provides background information related to the materials and specimens used to measure input parameters and their corresponding shrinkage stresses. Free drying shrinkage strain, restrained drying shrinkage stress and creep were measured from the first day after casting. Details of experimental works could be referred to Lange et al. (2003). Based on these data of input parameters (free drying shrinkage strain and creep), shrinkage stress is estimated using model of Eqs. (1.c) and (8.b). The results of calculation is compared with the shrinkage stress observed in restrained shrinkage stress measurement and presented in Fig. 11. As can be seen from this figure, computation of shrinkage stress with Eq. (8.b) will give almost similar value with the measured shrinkage. The difference in estimating shrinkage stress is only less than $10 \%$. The $10 \%$ overestimate value of shrinkage stress by Eq. (8.b) could be tolerated. Therefore, Eq. (8.b) may be accepted as a method to 
predict shrinkage stress when effect of substrate concrete properties is ignored. On the other hand, application of Eq. (1.c) will underestimate shrinkage stress by $30 \%$. Hence, Eq. (8.b) is favorable compared to Eq. (1.c).

\section{Simplified Model}

Method to estimate shrinkage stress required several input parameters which have to be experimentally determined simultaneously. Based on the values of input parameters, shrinkage stress could be computed and the risk of cracking on repair material could be assessed. Thus, input parameters may be used to set criteria for assessing shrinkage cracking tendency of repair material. If a model is developed with huge variety of parameters to be taken into account, it certainly will create complexity in setting criteria for assessing shrinkage cracking. For this reason, it is desirable to reduce the input parameters to as minimum as possible without losing in accuracy of the model for estimating shrinkage stress.

Beushausen and Alexander (2007) proposed simplified model to estimate shrinkage stress which requires less input parameter than models presented in previous section. Strain produced in patch repair is a combination of shrinkage, relaxation and elastic strain. For most specimens they tested, measured repair material strains on composite members were approximately $35 \%$ (between 30 and $40 \%$ ) of free repair material shrinkage strains $\varepsilon_{s h}$ and relaxation could be estimated to reduce tensile repair material stress by approximately $50 \%$. Therefore, they suggest strain which induces stress $\varepsilon_{\text {stress-producing }}$ in patching system as:

$$
\varepsilon_{\text {stress-producing }}=(1-0.35) 0.5 \varepsilon_{s h}=0.33 \varepsilon_{\text {sh }}
$$

This corresponds to shrinkage stress in repair material of:

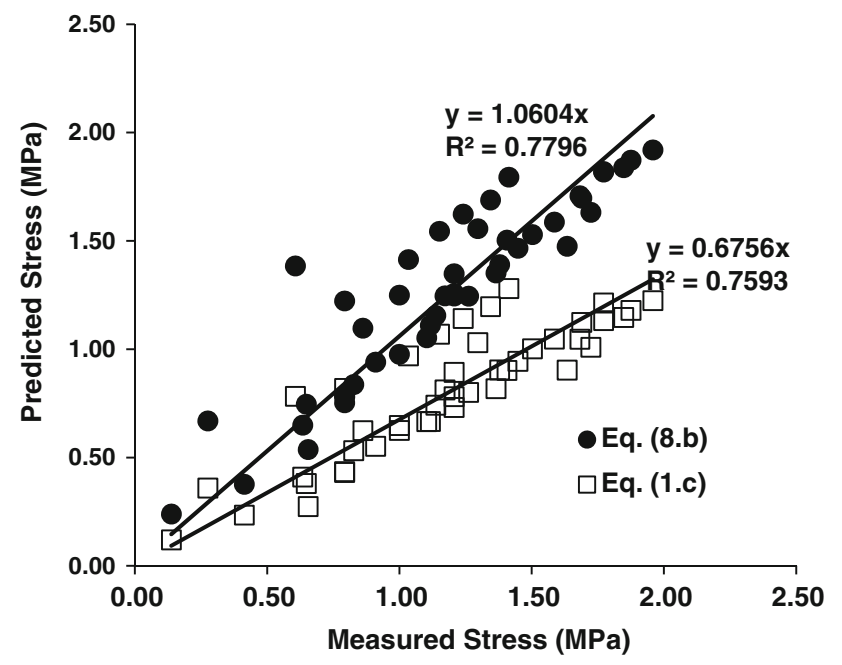

Fig. 11 Comparison between predicted and measured shrinkage stress (input parameters and measured shrinkage stress are extracted from Lange et al. (2003)).

$$
\sigma=0.33 E_{0} \varepsilon_{s h}
$$

where $E_{0}$ is elastic modulus of repair material. Thus, the simplified model requires only two input parameters i.e. elastic and shrinkage property of repair material.

A constant factor of 0.33 in Eq. (11) represents combination of degree of restraint due to creep and composite action. For degree of restraint provided by creep $\mu_{\phi}$ the value is equivalent to 0.5 and for that due to composite action $\mu_{c}$ it is equal to 0.65 (see Eq. (10)). Hence, if a comparison is made between Eq. (11) and other models, the following conclusions are drawn. It seems that the value of $\mu_{\phi}=0.5$ as suggested by Eq. (11) corresponds to average values of $\mu_{\phi}$ given by other models (see Fig. 5). Meanwhile, the value of $\mu_{c}=0.65$ matches with the mean values of $\mu_{c}$ as given in

Table 2 Information related to data used to validate model (after Lange et al. (2003)).

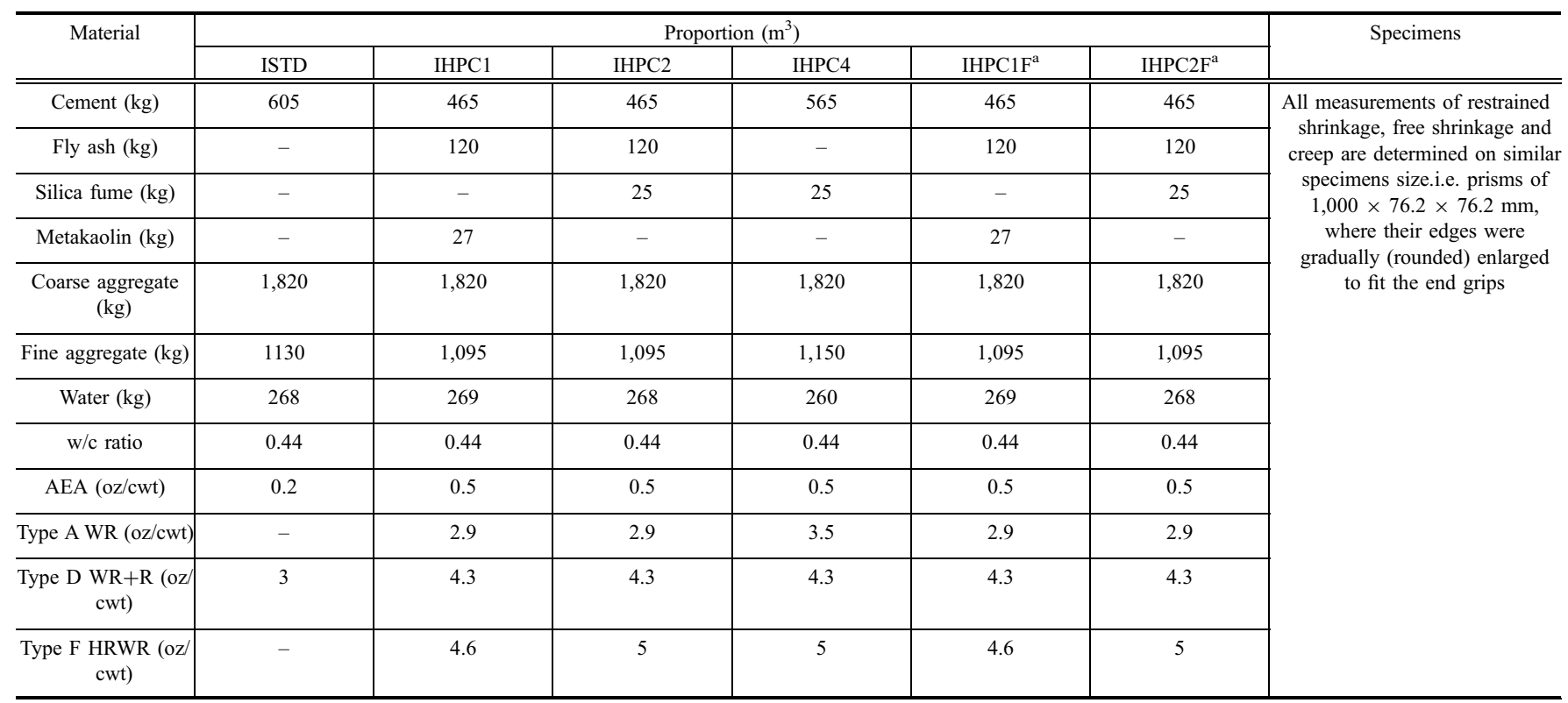

${ }^{\text {a }}$ Using field materials indicating difference sources to materials used in the laboratory. 


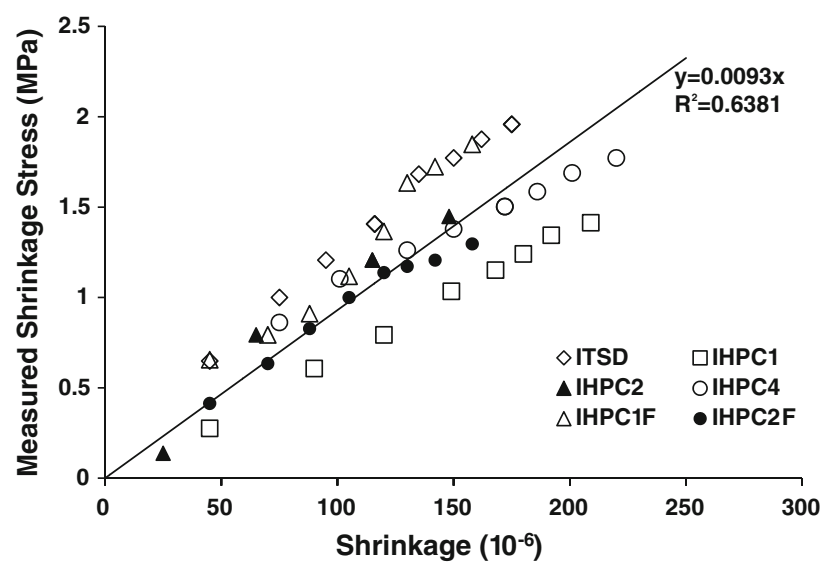

Fig. 12 Regression analysis to obtain simplified model.

Figs. 6 and 7 where the range of $\mu_{c}$ is from 0.44 to 0.87 . Thus, simplified model as given by Eq. (11) may be used to substitute model for estimating shrinkage stress in patch repair system where stress releases both due to creep and composite action are taken into account and the only available input parameters are shrinkage and elastic modulus of repair material.

Other simplified model has been proposed by Kristiawan (2011) where shrinkage stress at any time $t, \sigma_{(t)}$, may be calculated using the following equation:

$$
\sigma_{(t)}=0.0093 \varepsilon_{s h(t)}
$$

where $\varepsilon_{s h(t)}$ denotes shrinkage at time $t$; and the unit of stress and shrinkage is $\mathrm{MPa}$ and microstrain, respectively. The model is derived from regression analysis which relates the induced tensile stress with shrinkage. The data used for this analysis are taken from several literatures (Silfwerbrand 1996; Baluch et al. 2002; Weiss et al. 1998; Hossain et al. 2008). It should be noted that the shrinkage stresses employed in the regression analysis are those estimated from shrinkage stress prediction models. When actual shrinkage stresses as measured in the laboratory are used (Lange et al. 2003), similar result is obtained as seen in Fig. 12. Thus, complexity of the model is simplified by Eq. (12) where only shrinkage property is required to estimate shrinkage stress. All other factors influencing shrinkage stress in repair material are contained in the constant factor of 0.0093 . Since this simplified model is derived from data of measured shrinkage where restraint is provided by end restraint, the model (Eq. (12)) could only be used to substitute Eq. (8.b) where rigidity of substrate concrete is far greater than that of repair material as in the case of thin repair overlay system.

\section{Conclusions}

Various models to predict shrinkage stress in patch repair system has been suggested in literatures and the different values of shrinkage stress computed by these models could be traced from the difference degree of restraint and stress release considered by each model. Based on the provided data within the scope of the current study, the degree of restraint due to effect of creep $\mu_{\phi}$ is in the range of $0.1-0.9$. Meanwhile, the degree of restraint due to composite action $\mu_{c}$ is in the range of $0.44-0.87$.

Accuracy of the models to estimate shrinkage stress in patch repair system is evaluated based on available concurrent data of input parameters and observed shrinkage stress. For this current study it is confirmed that shrinkage stress estimated from model considering effect of creep to release stress (Eq. (8.b)) is slightly (not more than $10 \%$ ) higher than measured shrinkage stress. On the other hand, if elastic strain is also included (Eq. (1.c)), it will underestimates shrinkage stress by about $30 \%$. For this reason, Eq. (1.c) and other equation derived from this i.e. Eq. (4) are not recommended to be used for estimating shrinkage stress.

Two simplified models (Eqs. (11) and (12)) have been suggested where each of which has distinctive application. Equation (11) may be used to substitute model for estimating shrinkage stress in patch repair system where stress releases both due to creep and composite action are taken into account and the only available input parameters are shrinkage and elastic modulus of repair material. Meanwhile, Eq. (12) may be used to substitute Eq. (8.b) where the only stress release taken into account is that due to creep as in the case of thin repair overlay system and the available input parameter is the magnitude of shrinkage alone.

\section{Acknowledgments}

This work is part of comprehensive research to develop performance related criteria of patch repair system which is funded by Directorate General of Higher Education through Hibah Kompetensi (contract no. 134/SP2H/PL/Dit.Litabmas/III/2012).

\section{Open Access}

This article is distributed under the terms of the Creative Commons Attribution License which permits any use, distribution, and reproduction in any medium, provided the original author(s) and the source are credited.

\section{References}

AASHTO. (2006). Standard practice for estimating the crack tendency of concrete (pp. 34-99). Washington, DC: AASHTO Provisional Standards.

ASTM C1581. (2007). Standard test method for determining age at cracking and induced tensile stress characteristics of mortar and concrete under restrained shrinkage. West Conshohocken: ASTM.

ASTM C928-00. (2000). Standard specification for packaged dry rapid-hardening cementitious materials for concrete repairs. West Conshohocken: ASTM.

ASTM C1600-07. (2007). Standard test method for rapid hardening hydraulic cement. West Conshohocken: ASTM. 
Baluch, M. H., Rahman, M. K., \& Al-gadhib, A. H. (2002). Risks of cracking and delamination in patch repair. Journal of Materials in Civil Engineering, 14(4), 294-302.

Bentur, A., \& Kovler, K. (2003). Evaluations of early age cracking characteristics in cementitious system. Materials and Structures, 36, 183-190.

Beushausen, H., \& Alexander, M. G. (2007). Performance of concrete patch repair systems. In C. U. Grosse (Ed.), Advances in construction materials (pp. 255-262). Berlin: Springer.

Carlsward, J. (2006). Shrinkage cracking of steel fiber reinforced self compacting concrete overlays: Test methods and theoretical modelling. Doctoral thesis, Lulea University of Technology, Department of Civil and Environmental Engineering, Division of Structural Engineering, Luleå, Sweden.

Carlsward, J. (2008). Test methods and theoretical model to assess shrinkage cracking of steel fibre reinforced concrete overlays. Nordic Concrete Research, 38, 51-68.

Denarie, E., Silfwerbrand, J., \& Beushausen, H. (2011). Structural behaviour. in B. Bissonnette, L. Courard, D. W. Fowler, \& J. L. Granju (Eds.), Bonded-cement based material overlays for repair, the lining or the strengthening of slabs or pavements. State of the art reports of the RILEM technical committee 193-RLS (pp. 81-106). New York: Springer.

Hongkong Housing Authority. (1991). Practice notes for concrete repair. Hong Kong: Hongkong Housing Authority.

Hossain, A. B., Fonseka, A., \& Bullock, H. (2008). Early age stress development, relaxation and cracking in restrained low w/b ultrafine fly ash mortars. Journal of Advanced Concrete Technology, 6(2), 261-271.

Kristiawan, S. A. (2011). Compatibility of shrinkage between patch repair material and concrete (in Indonesian). Journal Teknik Sipil, 18(2), 103-118.

Kristiawan, S. A., Mahmudah, A. M. H., \& Sunarmasto. (2009). Cracking resistance of concrete overlays as predicted from the development of shrinkage stress. In Proceeding of $3 \mathrm{rd}$ international conference on concrete repair (pp. 157-160). Padua: ICCR.

Lange, D. A., Roesler, J. R., D’Ambrosia, M. D., Grasley, Z. J., Lee, C. J., \& Cowen, D. R. (2003). High performance concrete for transportation structures. Final report: prepared for Illinois Department of Transportation, Bureau of Materials and Physical Research. Urbana: Department of Civil and Environmental Engineering, The University of Illinois at Urbana-Champaign, Illinois, USA.

Matthews, S. (2007). CONREPNET: Performance based approach to the remediation of reinforced concrete structures: Achieving durable concrete structures. Journal of Building Appraisal, 3(2), 6-20.

McDonald, J. C., Vaysburd, A. M., \& Poston, R. W. (2000). Performance criteria for dimensionally compatible patch repair materials. HPM\&S Bulletin, 00-1, 1-13.

Rahman, M. K., Baluch, M. H., \& Al-Gadhib, A. H. (2000). Simulation of shrinkage distress and creep relief in concrete repair. Composites Part B Engineering, 31, 541-553.

Raoufi, K., Pour-Ghaz, M., Poursaee, A., \& Weiss, J. (2011). Restrained shrinkage cracking in concrete elements: Role of substrate bond on crack development. Journal of Materials in Civil Engineering, 23(6), 895-902.

Silfwerbrand, J. (1996). Differential shrinkage in normal and high strength concrete overlays. Nordic Concrete Research, 19, 55-68.

Weiss, W. J., Yang, W., \& Shah, S. P. (1998). Shrinkage cracking of restrained concrete slabs. Journal of Engineering Mechanics, 124(7), 765-774.

Yang, W., Weiss, W. J., \& Shah, S. P. (2000). Predicting shrinkage stress field in concrete slab on elastic subgrade. Journal of Engineering Mechanics, 126(1), 35-42.

Zhou, J., Ye, G., Schlangen, E., \& van Breugel, K. (2008). Modelling of stresses and strains in bonded concrete overlays subjected to differential volume changes. Theoretical and Applied Fracture Mechanics, 49, 199-205. 